\title{
Popularising astronomy in Iran
}

\author{
Babak A. Tafreshi ${ }^{1,2}$ \\ ${ }^{1}$ Nojum magazine, \\ P.O Box 15875-1487, Tehran, Iran \\ ${ }^{2}$ Astronomers Without Borders, \\ 26500 West Agoura Road, Suite 102-618, Calabasas, CA 91302, USA \\ email: btafreshi@twanight.org
}

\begin{abstract}
The interest to astronomy has incredibly risen in the younger generation of Iranians during the last two decades. By the end of the devastating war with Iraq, science popularisation activities started again in Iran and with only a handful of astronomers and few dozens of serious amateur astronomers in the whole country in late 1980s now there are thousands of amateur astronomers (60\% female on average) and over 100 professional astronomers propelling the fun and science of astronomy in the society.
\end{abstract}

Keywords. Iran, amateurs, popularisation, media, outreach

\section{Introduction}

Iran is a land of diversity in history, geography, nature, and culture. This is reflected in its 2500-year old society. Persia has a long history of astronomy with world-known astronomers such as Al-Sufi, Al-Biruni, and Al-Tusi and largest observatories in Islamic era such as Maraqa observatory. The new movement of astronomy in the recent years relives the old passion to the night sky among Persians. The majority of astronomy popularisation in Iran is made through publication of Nojum, a monthly Iranian astronomy magazine since 1991 which is the only popular magazine for astronomy in the Middle East (see the website, in Farsi, www.nojum.ir).

Although never making a conscious decision to become more than a magazine, Nojum has become a centre for organising popular astronomy and amateur activities in Iran. In a continues challenge with intense financial problems, a small group of editors led notable activities to relive astronomy in the country: holding astronomy classes and observing nights in schools and universities; maintaining an informative astronomy website; participating in television and radio programs; holding public star parties and astronomy conferences; assisting in the construction of educational observatories; sending information to Iranian media. Some of the editors even tried to bring astronomy to most remote sectors of the society, taking telescopes to youth prisons.

In a country plagued by political and financial problems, the popularisation of science is not always seen as relevant, and appeals for government sponsorship have thus far been rejected. Most contributors to the magazine are amateur astronomers, with a few professional astronomers and astronomy educators who volunteer their efforts.

\section{Overview}

While there were only a handful of general astronomy enthusiasts only two decades ago, there are currently several thousand amateur astronomers and about 100 amateur astronomy groups in the country Simmons (2001); Simmons \& Tafreshi (2003). Compared to generally old astronomy communication in many other countries the average age for 


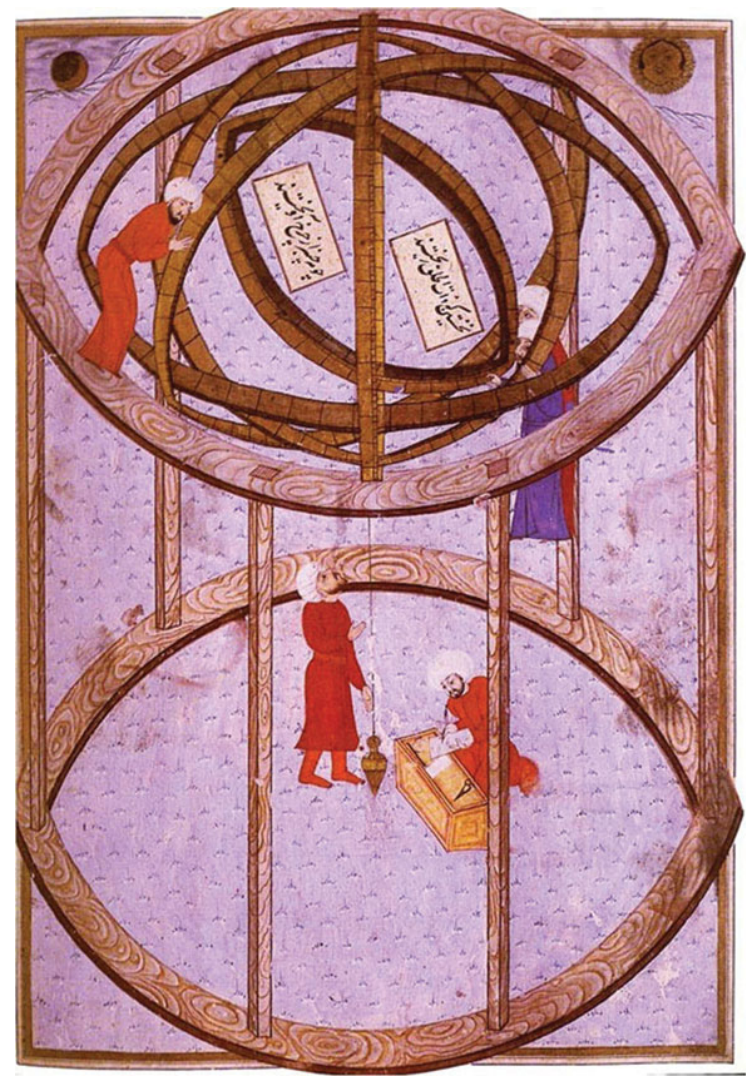

Figure 1. A scene from Maraqa observatory.

an amateur astronomer in Iran is close to 18. One reason for these young astronomers is that the Iranian society itself is young in average. Another surprise regarding amateur astronomy in Iran is that it attracts more women than men, not only by comparison with the hobby in the West but also with the common western perception of Islam as discouraging women from active participation in intellectual pursuits. Sixty percent of amateur astronomers in Iran are young women.

Besides the Nojum publication there were other propulsions for the burst of astronomy in Iran. Two total solar eclipses in Iran, in 1995 and 1999, and the 2004 historic transit of Venus brought immense public attention to astronomy. In 2001 a weekly dedicated astronomy program called "Asemane Shab" or the Night Sky in Persian, started on Iranian TV with contribution from Nojum editors. The program quickly turned to a widely popular program watched by over two millions in the program viewing peaks. The program has continued for 8 years now and generated notable astronomy enthusiasm in the society.

In early 2002 the Astronomical Society of Iran's outreach and amateur committee (ASIAC, www.asiac.ir/en) was founded to make better connections between the country's amateur astronomers and to organise national level programs. The Iran Messier Marathon which I founded in 2001 continued through ASIAC and turned to the national annual gathering of best amateur astronomers in a real observing competition above a roof a remote caravanserai in the middle of desert. In the recent years about 200 participants and guides attended the event from around the country. The Iran 


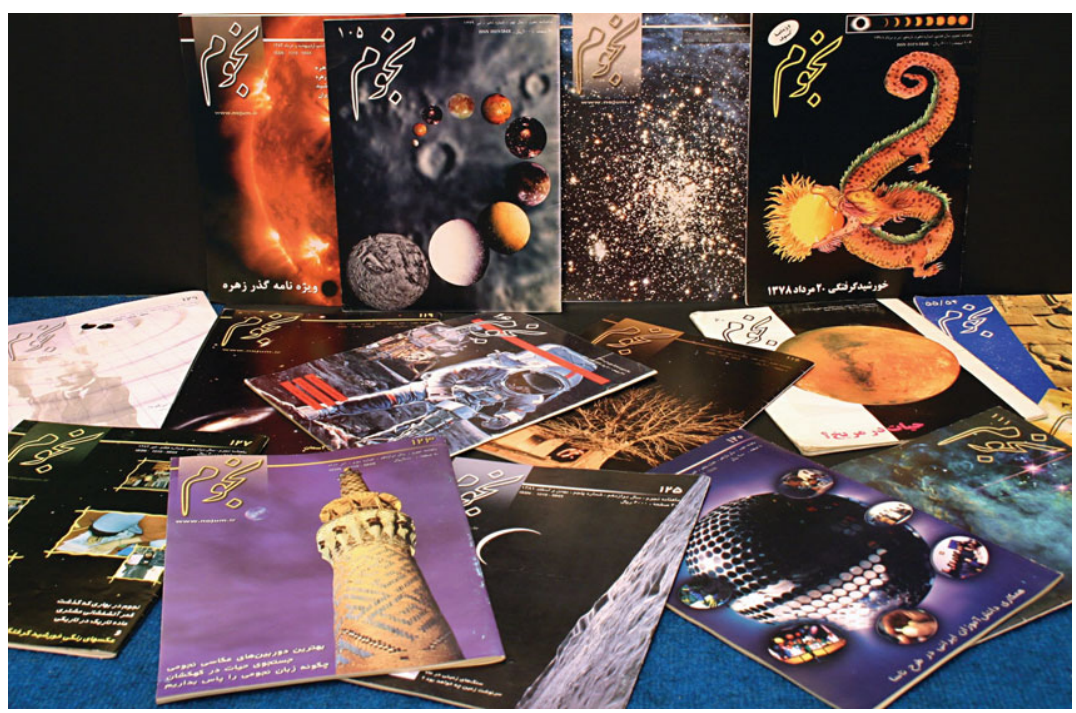

Figure 2. Covers from Nojum magazine.

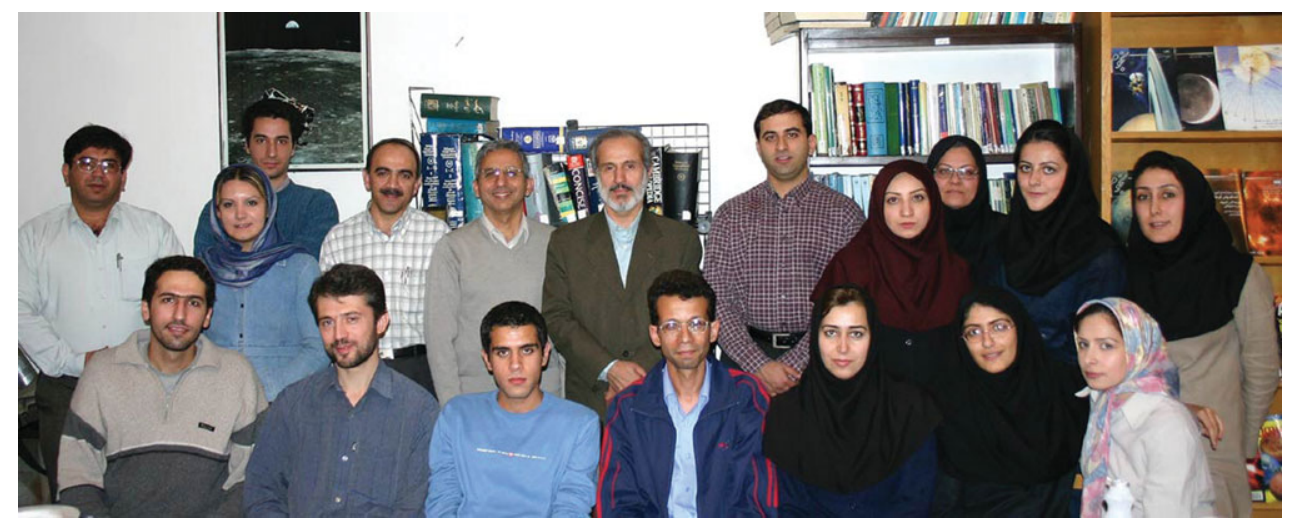

Figure 3. Staff members of Nojum magazine.

Messier Marathon seems to be the only national-level observing competition in the world which is organised annually. Since 2006 another country-wide competition started in a higher level for the most expert observers. The annual Sufi Observing Competition (www.sufioc.blogspot.com) which takes place in August/September is planned to be an international competition for advanced amateur astronomers from around the world. The competition's name is taken from the name of the famous Persian astronomer of the 10th century, Al-sufi (Azophi). In his reference book of stars he has noted to 9 non-stellar objects. Al-Sufi was the first astronomer in the history to record some of these deep sky objects such as the Andromeda galaxy.

Other annual astronomy popularising programs which are organised by ASIAC and held locally by astronomy groups in various locations of the country include the Astronomy Day (in April/May) and Week, Space Day (October 4), Winter Solstice celebration (the ancient Persian Yalda celebration on December 21), and the Sundial Festival on summer solstice (June 21) which plans to be an international program in future. Astronomy day and week activities were immensely carried out by amateur astronomers in the 
last years and ASIAC received the Astronomical League world's best prize for organising the astronomy day in 2006.

The encounter of long time beliefs, the religion and traditional life of Persians with the science of astronomy has been a unique experience for astronomy communicators in the country. For example the Islamic lunar calendar traditionally depends on sighting the Moon visually before a new month can begin. Today young Moon sighting is an exciting activity for many amateur astronomers in Iran that can be pursued with small telescopes, binoculars or even naked eye. The world record for the youngest visually observed moon is currently in hand of an Iranian observer who caught the Moon using a giant binocular on September 7, 2002, at 11 hours and 40 minutes after the new Moon (see R. Sinnott's 2004 Sky 85 Telescope note at ww..skyandtelescope.com/observing/objects/projects/ 3308686.html).

In some areas of the country astronomy has been merged with local traditions and the daily life. The greatest enthusiasm for astronomy is found in the small town of SaadatShahr in Iran's southern Fars province. The agricultural town is located close to the ancient tomb of Cyrus the Great, the creator of Persian Empire. High on a hill in the suburbs of Saadat-shahr an observatory financed solely by donations from the less than wealthy population -including women who have sold their jewelry to raise money- is taking shape. On the nights of important star parties municipal officials briefly shut off all power to the town to eliminate light pollution. The widespread devotion of this town to astronomy is due in large part to the work of a local teacher and astronomy populariser, Asghar Kabiri, who received the international Amateur Outreach award for 2006 from the Astronomical Society of Pacific (see www . astrosociety .org/membership/awards/bios/kabiri.html).

Saadat-shahr or the so-called "Astronomy Town" has many other surprises. Most wedding ceremonies end with star party and telescopic observation; some streets are named after Persian and western historic astronomers; some taxies/doctors/bakeries are free during the astronomy week; the astronomical society of the town present weekly sky reports after the Friday prayers in the main mosque.

While astronomy experienced a burst of popularisation in Iran, major educational and public centers for astronomy which need to be founded by the government are still very limited, as well as high-technology telescopes for advanced amateur and professional astronomers. About 30 observatories exist in the country which most of them are for amateur astronomy and public use, and only few works for research using 30-60 centimetre reflectors. The professional astronomers are all registered with the Astronomical Society of Iran (ASI, www.asi.ir/index_e.asp). As to 2009 there are less than 100 astronomers, mostly in theoretical astrophysics and cosmology. The lack of large and modern telescope for this growing group of astronomers, created the Iran National Observatory (INO, www.ino.org.ir) project. After difficult challenges to get founding from the government and dealing with western sanctions, it has now secured international collaborators to make a 3-meter class modern telescope which will be located under dark transparent sky of Iran's central desert mountains (Stone 2005).

\section{References}

Simmons, M. 2001, Sky \& Telescope, 101, 76

Simmons, M. \& Tafreshi, B. A. 2003, Mercury, 32, 28

Stone, R. 2005, Science, 308, 1802 